\title{
The Beneficiary Role of Selenium in Type II Diabetes: A Longitudinal Study
}

Dimitrios T. Karalis ${ }^{1}$

1. Pathology, University of Thessaly, Volos, GRC

Corresponding author: Dimitrios T. Karalis, karalis_dim@yahoo.gr

\section{Abstract \\ Introduction}

Selenium (Se) is an antioxidotic element that is able to protect the pancreatic islets from oxidative stress, improve their functionality, and suspend atherosclerosis. The current paper is an attempt to demonstrate the beneficiary impact of administrating Se to patients with diabetes type 2 who are being treated with oral hypoglycemic agents, based on their glycemic and lipidemic profile.

\section{Methods}

The study involves 94 individuals, 72 male and 22 female patients aged 48 to 64 years old with diabetes mellitus type 2 . They did not present any diabetic complications or significant comorbidities. They were following a Mediterranean diet and were monitored in order to maintain a steady body mass index (BMI). They were administered with Se $200 \mu$ g, taken once daily on an empty stomach. The laboratory testing included fasting blood glucose, hemoglobin A1c (HbA1c), total cholesterol, triglycerides, high-density lipoprotein (HDL), and low-density lipoprotein (LDL). The tests were performed before, three months after, and six months after the administration of selenium.

\section{Results}

The study resulted in a statistically significant reduction in the blood levels of glucose, HbA1c, cholesterol, and LDL in both three months and six months after the beginning of the treatment. HDL did not present any change during the first three months but did present a statistically significant increase in six months.

Triglycerides did not present a significant reduction in both three and six months.

\section{Conclusion}

It appears that the administration of Se to type-2 diabetic patients can improve their glycemic and lipidemic profile, while larger definite trials are needed to provide further evidence.

Received 12/10/2019

Review began 12/15/2019 Review ended 12/20/2019 Published 12/22/2019

○) Copyright 2019

Karalis. This is an open access article distributed under the terms of the Creative Commons Attribution License CC-BY 3.0., which permits unrestricted use, distribution, and reproduction in any medium, provided the original author and source are credited.
Categories: Endocrinology/Diabetes/Metabolism, Pathology

Keywords: type 2 diabetes, selenium, oxidative stress, hba1c, hdl, ldl, cholesterol, glucose, triglycerides, clinical trial

\section{Introduction}

Selenium (Se) is a mineral that is characterized as semi-metal or as a metalloid and is positioned in place 34 on the periodic table [1]. Se was discovered in 1818 by the Swedish Jons Jacob Berzelius; in 1957, Schwarz and Foltz identified it as being essential for human life [2]. Se exists in nature both in inorganic and organic form. In the organic form, Se is connected with proteins which are called selenoproteins [3]. The main organic forms are selenomethionine and selenocysteine [4].

Sources rich in Se are seafood, entrails, dairy products, grains, cereals and Brazilian nuts [5]. Se is a structural component of many enzymes such as glutathione hyperoxidase, Thioredoxin-Reduktase, deiodinase-lodothyronine and selenoprotein P [6]. Glutathione hyperoxidase includes selenocysteine [7] and constitutes a fundamental antioxidant component since it catalyzes the removal of organic hyper-oxides and hydrogen peroxide $\left(\mathrm{H}_{2} \mathrm{O}_{2}\right)$ from the tissues [8]. If these are taken out from the human body, they become toxic for cellular membranes and they will contribute to their destruction [7].

The present study attempts to propose Se as a dietary supplement (and not as a medicine) that can play a beneficiary role in type II diabetes. The participants were euglycemic and followed anti-diabetes treatment according to the protocols. Blood sugar was under control; therefore, our main goal was to enhance the therapeutic effect (interventional value of Se).

\section{Materials And Methods \\ Hypothesis}


Oxidative stress has a huge impact on the etiology, pathogenesis, and the complication of type II diabetes. Due to its oxidative effect, glutathione hyperoxidase could play a crucial role against type II diabetes [9-10]. The excess of glutathione hyperoxidase in the pancreas could not only protect $\beta$-cells from oxidative stress but also improve their function. However, high dosages of Se could negatively affect the development of type II diabetes [9].

It is also hypothesized that antioxidants play an important role in fighting cardiovascular diseases by increasing the resistance of low-density lipoprotein (LDL) in oxidative modification. This boosts the formation of atherosclerotic plaques by regulating the synthesis of prostaglandin, accumulating blood cells, and protecting the organism against heavy metals (mercury) which have a toxic effect on the cardiovascular system [10-11]. The recommended average daily dosage of Se in adults is approximately $200 \mathrm{mg}$ [12]. The present study hypothesizes that Se can improve the development of type II diabetes and risk factors of cardiovascular disease.

\section{Methodology}

Prior to the main study, we have conducted a pilot study. The control group involved 40 participants. They were given a placebo. The results showed a non-statistically significant decrease in blood sugar and hemoglobin A1c (HbA1c). Total cholesterol, triglycerides, and low-density lipoprotein (LDL) cholesterol levels showed no change. High-density lipoprotein (HDL) cholesterol showed a small increase; however, it was not statistically significant. Both in the pilot study and in the main study, participants gave their written consent (according to the protocols of the National Ethics Committee for Clinical Studies).

In the main study, we have gathered 92 Greek patients, 70 males and 22 females, ranging from 48 to 64 years of age. All of them were smokers (approximately 20 cigarettes per day) and were diagnosed with type II diabetes. They were under medical surveillance, on anti-diabetic tablets, and they were relatively euglycemic. Their diet was under surveillance in accordance with the standards of the Mediterranean diet (carbohydrates: $50 \%$, proteins: $18 \%-20 \%$, fats: 32\%-30\%). They also had a stable daily intake of calories (2400-2600 kcal/day) so as to avoid any modifications in their body mass index (BMI). In the beginning of the study, their BMI was 30 and we have observed a relatively small decrease which was not statistically significant (work in progress to appear within 2019). The patients did not have any complications of type II diabetes and they did not have a record of other diseases.

They were given $200 \mathrm{mg}$ Se on a daily basis (without eating for four hours before taking the medication) for six months. The values of fasting glucose, HbA1c, blood total cholesterol, triglycerides, HDL, and LDL were measured within the time periods of zero, three, and six months after the beginning of the medication of 200 $\mathrm{mg}$ Se/day.

Fasting glucose was determined by the colorimetric method (normal values: $75-115 \mathrm{mg} / \mathrm{d}$ ). HbA1c was determined by the high-performance liquid chromatography (HPLC) method (desirable percentage < 7\%). Blood total cholesterol (normal values: $150-200 \mathrm{mg} / \mathrm{dl}$ ) and triglycerides (normal values: 20-170 mg/dl) were measured by the enzymic colorimetry method.

\section{Results}

The results were studied using the Statistical Package for the Social Sciences software (SPSS Inc., Chicago, IL). The distribution of differences in the dependent variable between the two groups was demonstrated normally since we were given a sample of $n=92(>50)$ participants.

The administration of medication after three months lead to a significant decrease in blood glucose levels: 16,53 (mean=16,53). The results were statistically significant $(\mathrm{p}=0,00001<0,05)$. After six months of medication, the decrease of glucose was 17,21 (mean=17,21) compared to the day $0(\mathrm{p}=0,00001<0,5)$ as shown in Table 1 and Figure 1. 


\section{Cureus}

\begin{tabular}{|c|c|c|c|c|c|c|c|c|}
\hline & \multirow{2}{*}{$\mathbf{N}$} & \multirow{2}{*}{ Range } & \multirow{2}{*}{ Minimum } & \multirow{2}{*}{ Maximum } & \multicolumn{2}{|l|}{ Mean } & \multirow{2}{*}{ Std. Deviation } & \multirow{2}{*}{ Variance } \\
\hline & & & & & Value & Std. Error & & \\
\hline Glucose_Before & 92 & 67 & 107 & 174 & 130,67 & 1,338 & 12,838 & 164,816 \\
\hline Glucose_after_3_Months & 92 & 130,8 & 9,2 & 140 & 114,143 & 1,6307 & 15,6413 & 244,65 \\
\hline Glucose_after_6_Months & 92 & 58 & 86 & 144 & 113,457 & 1,2334 & 11,8307 & 139,965 \\
\hline Valid N (listwise) & 92 & & & & & & & \\
\hline
\end{tabular}

TABLE 1: Glucose descriptive statistics (zero, three, and six months)

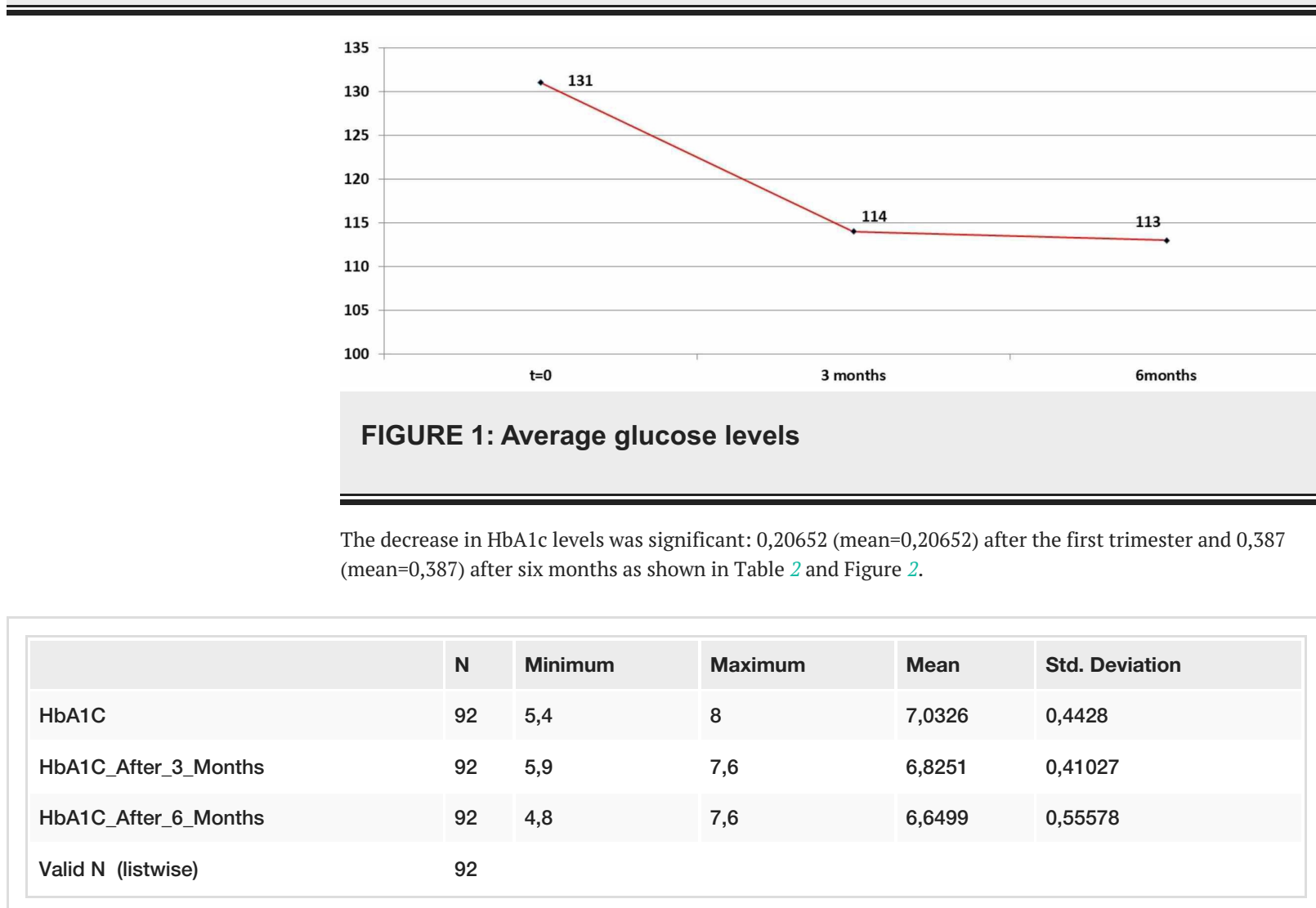

TABLE 2: HbA1c descriptive statistics (zero, three, and six months)

HbA1c: hemoglobin A1c

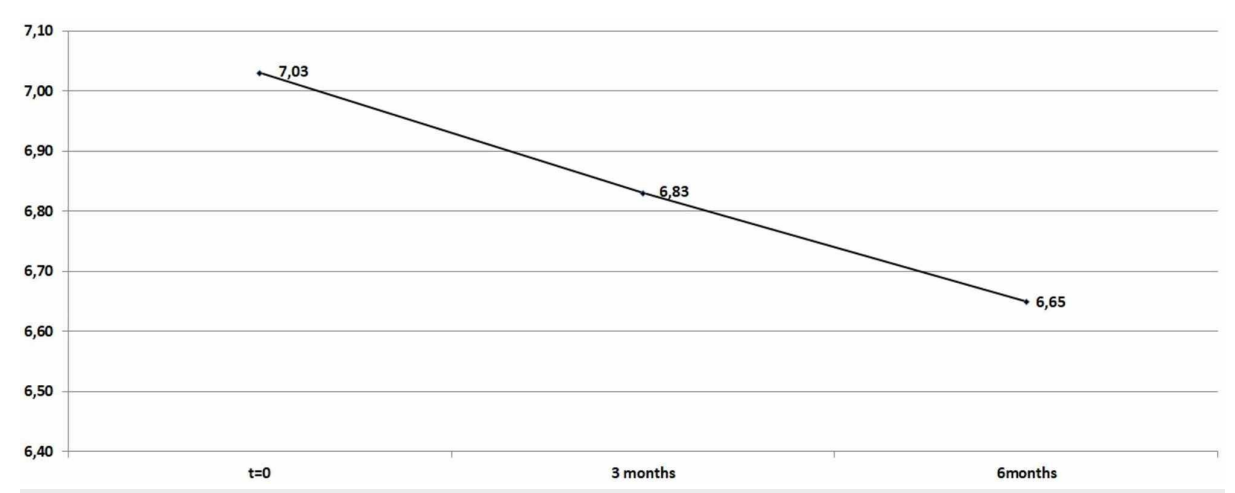

FIGURE 2: Average HbA1c levels 


\section{Cureus}

HbA1c: hemoglobin A1c

Moreover, the average value of blood total cholesterol ranged between 12,7463 and 19,7102 after three months of medication in Se and continued to drop after six months of medication (mean=27,7826).

Therefore, the difference in blood total cholesterol levels as observed in the two time periods is highly significant as shown in Table 3 and Figure 3 .

\begin{tabular}{|l|l|l|l|l|l|}
\hline & N & Minimum & Maximum & Mean & Std. Deviation \\
\hline Cholesterol & 92 & 178 & 254 & 214,543 & 18,5131 \\
\hline Cholesterol_After_3_Months & 92 & 168 & 238 & 198,315 & 12,5365 \\
Cholesterol_After_6_Months & 92 & 165 & 224 & 186,751 & 10,9849 \\
Valid N (listwise) & 92 & & & & \\
\hline
\end{tabular}

TABLE 3: Cholesterol descriptive statistics (zero, three, and six months)

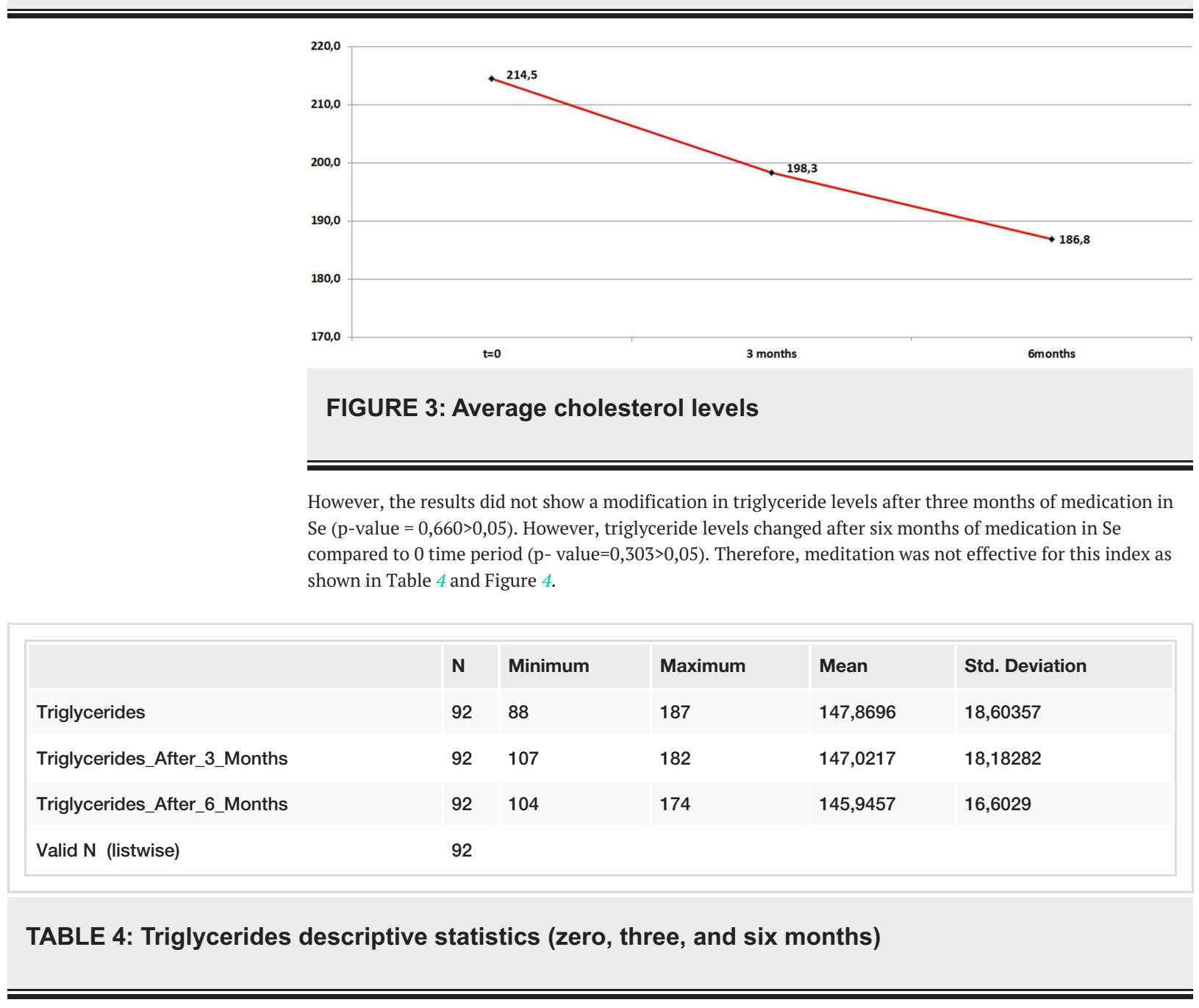




\section{Cureus}

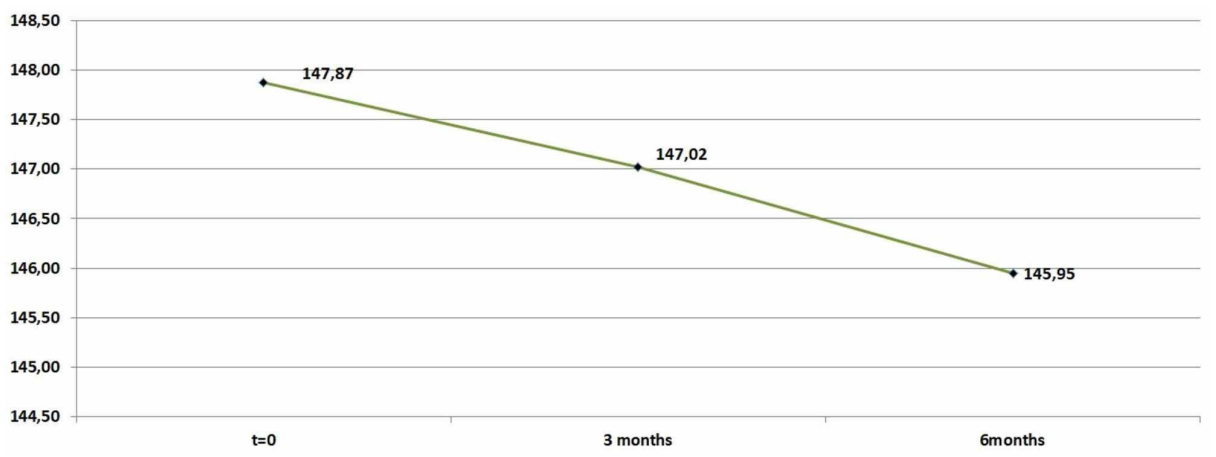

FIGURE 4: Average triglyceride levels

As far as HDL levels are concerned, it could be ascertained (95\%) that the average increase in HDL levels: 1,097 (mean-1,097) was not statistically significant ( $\mathrm{p}$-value $=0,098>0,05$ ) for the first trimester. However, it was statistically significant $(\mathrm{p}=0,00001<0,05)$ after the time period of six months due to its increase (mean=3,4103) as shown in Table 5 and Figure 5.

\begin{tabular}{|c|c|c|c|c|c|}
\hline & $\mathbf{N}$ & Minimum & Maximum & Mean & Std. Deviation \\
\hline HDL & 92 & 22 & 54 & 39,7609 & 5,93809 \\
\hline HDL_After_3_Months & 92 & 30 & 50 & 40,8587 & 4,94937 \\
\hline HDL_After_6_Months & 92 & 31 & 56 & 43,1739 & 5,42199 \\
\hline Valid N (listwise) & 92 & & & & \\
\hline
\end{tabular}

TABLE 5: High-density lipoprotein (HDL) descriptive statistics (zero, three, and six months)

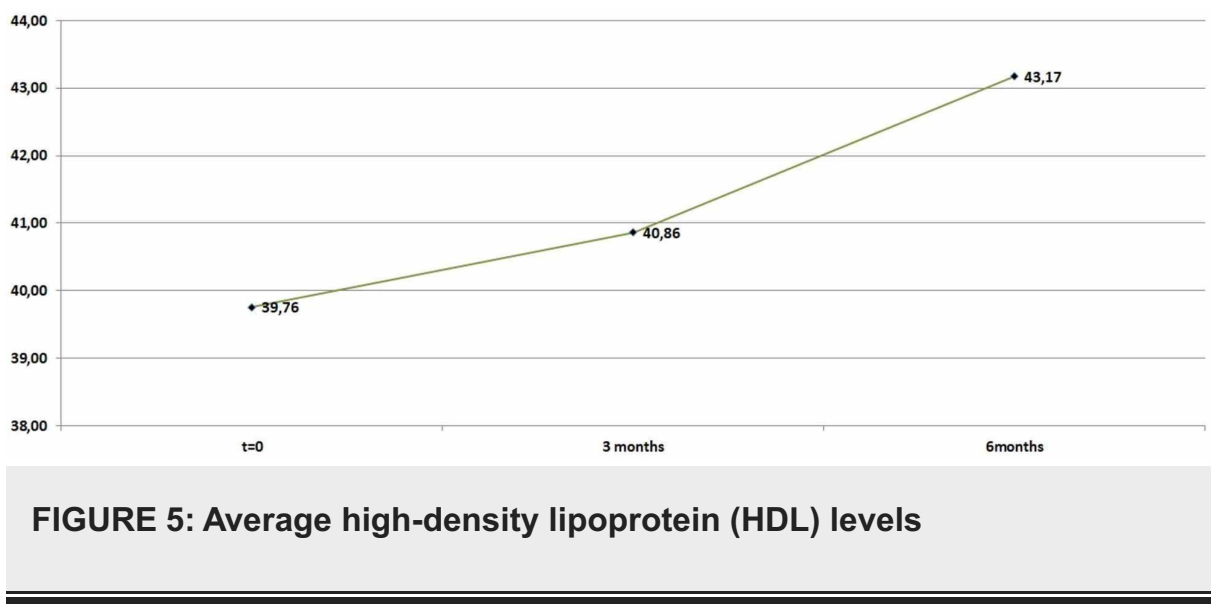

Finally, LDL levels dropped significantly $(\mathrm{p}=0,0001)$ both for the time period of three months (mean $=8,2065)$ and for the time period of six months (mean=15,50) as shown in Table 6 and Figure 6. 


\section{Cureus}

\begin{tabular}{|c|c|c|c|c|c|}
\hline & $\mathbf{N}$ & Minimum & Maxımum & Mean & Std. Deviation \\
\hline LDL & 92 & 110 & 198 & 146,0435 & 17,9345 \\
\hline LDL_After_3_Months & 92 & 100 & 197 & 137,837 & 17,19397 \\
\hline LDL_After_6_Months & 92 & 97 & 180 & 130,5435 & 17,4264 \\
\hline Valid N (listwise) & 92 & & & & \\
\hline
\end{tabular}

TABLE 6: Low-density lipoprotein (LDL) descriptive statistics (zero, three, and six months)

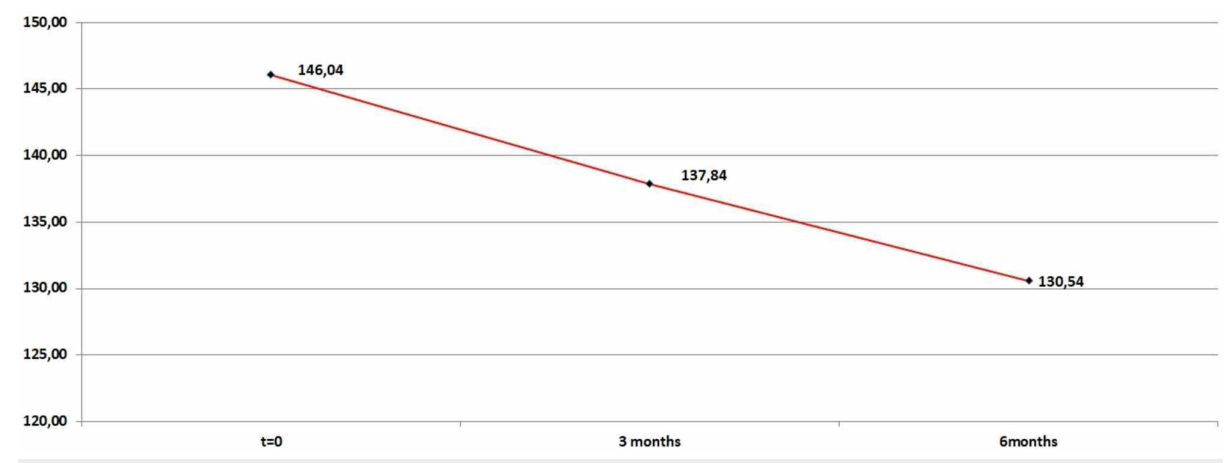

FIGURE 6: Average low-density lipoprotein (LDL) levels

\section{Discussion}

There are not enough studies investigating the effect of Se in lipid profile and blood glucose. The present study showed that the administration of Se in the recommended dosages improves the values of fasting glucose, HbA1c, blood total cholesterol, HDL and LDL. However, there was not a significant difference in triglyceride levels. Different analyses of the Greek Healthcare System showed that increased (above average) Se levels in plasma relate with adverse lipid profile.

Many studies stated that there was a correlation between dietary supplements and Se due to increased triglycerides and LDL levels. However, HDL levels dropped [13]. A study in diabetic patients showed that they may suffer from Se deficiency compared to non-diabetic patients [14]. A study conducted in France showed that elderly males with high Se levels had a lower risk of developing type II diabetes or having abnormal fasting glucose levels. Elderly females, however, did not run this risk at all [15].

In the USA, a study examined adults who were administered Se in the past. It was observed that HBA1C levels increased in proportion to Se levels [16-17]. Another longitudinal study examined Se levels in the nails of the big toes and showed that higher Se levels in nails relate to a lower risk of developing type II diabetes [18].

Lee et al. observed that individuals with low Se levels had an increased atherogenic index and lower HDL levels compared to individuals with higher Se levels. The correlation between Se levels and atherogenic index was tested only in females below 40 years of age [19].

Moreover, a study in Poland which was conducted in 2013 showed that Se supplements improved HBA1C levels but not fasting glucose levels [20]. However, a study conducted in Taiwan examined elderly individuals and found out that higher Se levels had a correlation with higher fasting glucose levels and with higher blood total cholesterol and triglyceride levels [21].

In 2016, a study on elderly individuals which was conducted in China ascertained that Se levels relate to type II diabetes due to increased glucose levels and their resistance to insulin [22]. Other Chinese scientists who carried out experimental studies during 2016 found out that increased Se levels relate with a more frequent presence of non-alcoholic fatty liver disease (NAFLD) and with increased triglyceride levels, LDL, fasting glucose, HBA1C, and insulin resistance [23].

Therefore, a comparison of the aforementioned findings suggests that there is a relative improvement after Se administration. However, there is no identical ground among the studies. Since there is a blank in the 
literature concerning the medicinal role of Se, the present research approaches it as a dietary supplement. It is suggested that as a dietary supplement, Se enhances the glycemic and lipidemic profile of type II diabetes patients because it can improve the effectiveness of their therapeutic treatment. It is likely that Se helps in delaying the development of pre-diabetes.

\section{Conclusions}

The present study enforces the claims concerning the multiple benefits of Se as a dietary supplement in patients with type II diabetes under the prerequisite of following the Mediterranean diet as the recommended treatment method. Even though the present research is at an early stage, we could suggest that Se constitutes a necessary dietary supplement.

\section{Additional Information \\ Disclosures}

Human subjects: Consent was obtained by all participants in this study. National Ethics Committee for Clinical Studies issued approval 55480/6-09-2006. Both in the pilot study and in the main study participants gave their written consent (according to the protocols of the National Ethics Committee for Clinical Studies). They were all patients in Dr. Karalis private office and they were aware of taking part in a study. Animal subjects: The Greek legislation concerning interventional clinical trials on investigational medicinal products (CTIMPs) was published in the Greek Republic Gazette No 1973 of 31 December 2003. It refers to the Minister of Health's decision DYG 3/89292, which describes the law under which the Directive 2001/20/EC was adopted in Greece. The law has no title, as all laws in Greece are referred to by number. Standard Operating Procedures for the National Ethics Committee were published in the Greek Republic Gazette No 1503 of 7 October 2004, referring to the Minister of Health's decision DYG 3(A) 69150. Issued protocol number No 1503. Conflicts of interest: In compliance with the ICMJE uniform disclosure form, all authors declare the following: Payment/services info: All authors have declared that no financial support was received from any organization for the submitted work. Financial relationships: All authors have declared that they have no financial relationships at present or within the previous three years with any organizations that might have an interest in the submitted work. Other relationships: All authors have declared that there are no other relationships or activities that could appear to have influenced the submitted work.

\section{References}

1. Puddephatt RJ, Monaghan PK: The Periodic Table of the Elements . Oxford University Press, Oxford; 1987.

2. Riaz M, Mehmood KT: Selenium in human health and disease: a review . J Postgrad Med Inst. 2012, 26:12033.

3. Davis CD: Selenium supplementation and cancer prevention. Curr Nutr Rep. 2012, 1:16-23. 10.1007/s13668011-0003-X

4. Bates CJ: Selenium. Encyclopedia of Human Nutrition. Caballero B, Allen I, Prentice A (ed): Elsevier, Amsterdam; 2005.

5. Ogawa-Wong AN, Berry MJ, Seale LA: Selenium and metabolic disorders: an emphasis on type 2 diabetes risk. Nutrients. 2016, 8:80. 10.3390/nu8020080

6. Mehdi Y, Hornick JL, Istasse L, Dufrasne I: Selenium in the environment, metabolism, and involvement in body functions. Molecules. 2013, 18:3292-3311. 10.3390/molecules 18033292

7. Gropper SS, Smith JL, Groff JL: Nutrition and Metabolism. Paschalides Medical Publishing, Athens; 2008.

8. Rotruck JT, Pope AL, Ganther HE, Swanson AB, Hafeman DG, Hoekstra WG: Selenium: biochemical role as a component of glutathione peroxidase. Science. 1973, 179:588-590. 10.1126/science.179.4073.588

9. Wang XL, Yang TB, Wei J, Lei GH, Zeng C: Association between serum selenium level and type 2 diabetes mellitus: a non-linear dose-response meta-analysis of observational studies. Nutr J. 2015, 15:48. 10.1186/s12937-016-0169-6

10. Ayaz M, Turan B: Selenium prevents diabetes-induced alterations in [Zn2] and metallothionein level of rat heart via restoration of cell redox cycle. Am J Physiol Heart Circ Physiol. 2006, 290:H1071-H1080. 10.1152/ajpheart.00754.2005

11. British Nutrition Foundation: Briefing paper. BNF Publications, London; 2001.

12. Institute of Medicine (US) Panel on Dietary Antioxidants and Related Compounds: Dietary Reference Intakes for Vitamin C, Vitamin E, Selenium, and Carotenoids. National Academies Press (US), Washington DC; 2000.

13. Tanguy S, Grauzam S, de Leiris J, Boucher F: Impact of dietery selenium intake on cardiac heath: experimental approaches and human studies. Mol Nutr Food Res. 2012, 56:1106-1121. 10.1002/mnfr.201100766

14. Stranges S, Marshall JR. Natarajan R, et al.: Effects of long-term selenium supplementation on the incidence of type 2 diabetes: a randomized trial. Ann Intern Med. 2007, 147:217-223. 10.7326/0003-4819-147-4200708210-00175

15. Akbaray TN, Arnaud J, Rayman MP, Hininger-Favier I, Roussel AM, Berr C, Fontbonne A: Plasma selenium and risk of dysglycemia in an elderly French population: results from the prospective Epidemiology of Vascular Ageing Study. Nutr Metab. 2010, 7:21. 10.1186/1743-7075-7-21

16. Laclaustra M, Navas-Acien A, Stranges S, Ordovas JM, Guallar E: Serum selenium concentrations and diabetes in USA adults: National Health and Nutrition Examination Survey. Environ Health Perspect. 2009, 117:1409-1413. 10.1289/ehp.0900704 


\section{Cureus}

17. Bleys J, Navas-Acien A, Guallar E: Serum selenium and diabetes in U.S. adults. Diabetes Care. 2007, 30:829834. 10.2337/dc06-1726

18. Park K, Rimm EB, Siscovick DS, et al.: Toenail selenium and incidence of type 2 diabetes in U.S. men and women. Diabetes Care. 2012, 35:1544-1551. 10.2337/dc11-2136

19. Lee O, Moon J, Chung Y: The relationship between serum selenium levels and lipid profiles in adult women [Article in English, Japanese]. J Nutr Sci Vitaminol. 2003, 49:397-404. 10.3177/jnsv.49.397

20. Jablonska E, Reszka E, Gromadzinska J, et al.: The effect of selenium supplementation on glucose homeostasis and the expression of genes related to glucose metabolism. Nutrients. 2016, 8:772. 10.3390/nu8120772

21. Yang KC, Lee LT, Lee YS, Huang HY, Chen CY, Huang KC: Serum selenium concentration is associated with metabolic factors in the elderly: a cross-sectional study. Nutr Metab. 2010, 7:38. 10.1186/1743-7075-7-38

22. Su LQ, Jin YL, Unverzagt FW, et al.: Nail selenium level and diabetes in older people in rural China . Biomed Environ Sci. 2016, 29:818-824. 10.3967/bes2016.109

23. Yang Z, Yan C, Liu G, et al.: Plasma selenium levels and nonalcoholic fatty liver disease in chinese adults: a cross-sectional analysis. Sci Rep. 2016, 6:37288. 10.1038/srep37288 